\title{
Categorical Semantics of Dependent Taxis in Russian Language
}

\section{Arkhipova Irina Viktorovna ${ }^{1}$}

Professor, Novosibirsk State Pedagogical University, Novosibirsk, Russia.

(date of receiving: August, 2020; date of acceptance: October, 2020)

\begin{abstract}
This article discusses the categorical semantics of the dependent taxis and its actualization in Russian statements with prepositional deverbatives. Statements with prepositional deverbatives constitute a micro-field of dependent taxis in the Russian language and differ in heterogeneity and various degrees of prototypically. Statements of chronological type with taxis-forming prepositions of temporal semantics во время, в течение, после, перед, до, с, при, накануне form the sphere of primary (primal, chronological, logically unconditioned) taxis. In statements of a logically conditioned type with heterogeneous-taxis prepositions of non-temporal semantics несмотря на, вопреки, в силу, благодаря, из-за, от, вследствие, ради, для represent the values of secondary (adverbial, circumstance, logically conditioned) taxis. In statements of the multiple type with iterative deverbatives, verbs and in the presence of iterative quantifiers of the tyре: каждый раз, всякий раз, часто, всегда, иногда, регулярно аnd others, various conjugate iterative-taxis categorical situations of simultaneity, precedence and consecutive are actualized: iterative-primary taxis and iterative-secondary-taxis (in "pure form" or with circumstantial elements of logical conditioning).
\end{abstract}

Keywords: Taxis, Dependent Taxis, Primary Taxis, Secondary Taxis, Primary Taxis Values, Secondary Taxis Values, Iterative Taxis Categorical Situations.

1. E-mail: irarch@yandex.ru 


\section{Категориальная семантика зависимого таксиса в русском языке}

\section{Архипова Ирина Викторовна ${ }^{1}$}

Профессор, Новосибирский государственный педагогический университет, Новосибирск, Россия.

(дата получения: август 2020 г.; дата принятия: октябрь 2020 г.)

\section{Аннотация}

В настоящей статье рассматривается категориальная семантика зависимого таксиса и еe актуализация в русских высказываниях с предложными девербативами.

Высказывания с предложными девербативами конституируют микрополе зависимого таксиса в русском языке и отличаются гетерогенностью и различной степенью прототипичности.

Высказывания хронологического типа с таксисообразующими предлогами темпоральной семантики во время, в течение, после, перед, до, с, при, накануне образуют сферу примарного (первичного, хронологического, логически необусловленного) таксиса.

Высказывания логически обусловленного типа с гетерогенно-таксисными предлогами нетемпоральной семантики несмотря на, вопреки, в силу, благодаря, из-за, от, вследствие, ради, для репрезентируют значения секундарного (обстоятельственного, сирконстантного, логически обусловленного) таксиса.

В высказываниях кратного типа с итеративными девербативами, глаголами и при наличии итеративных квантификаторов типа: каждый раз, всякий раз, часто, всегда, иногда, регулярно и др. актуализируются различные сопряженные итеративно-таксисные категориальные ситуации одновременности, предшествования и следования: итеративно-примарно-таксисные и итеративносекундарно-таксисные (в «чистом виде» или с обстоятельственными элементами логической обусловленности).

Ключевые слова: Таксис, Зависимый Таксис, Примарный Таксис, Секундарный Таксис, Примарно-таксисные Значения, Секундарно-таксисные Значения, Итеративно-таксисные Категориальные Ситуации.

1. E-mail: irarch@yandex.ru 


\section{Введение}

В фокусе исследовательского внимания описание категориальной семантики зависимого таксиса и ее актуализация в русских высказываниях с предложными девербативами.

Р.О. Якобсон впервые в 1972 году вводит понятие «таксис», отмечая, что он, будучи нешифтерной категорией, «характеризует сообщаемый факт по отношению к другому сообщаемому факту и безотносительно к факту сообщения» (Якобсон 1972. 95-114).

Ю.С. Маслов разграничивает две сферы: хронологический таксис (временные отношения) и логический таксис (причинно-следственные, условные, уступительные, целевые отношения), выделяя: (1) таксисные формы, обозначающие хронологическое соотношение, 2) таксисные формы, которые прототипически являются синтаксически зависимыми и обозначают второстепенное действие (Маслов 1983. 42).

В.Б. Касевич указывает на то, что различие между зависимым и независимым таксисом носит формально-грамматический характер. Он отмечает, что «о зависимом и независимом таксисе можно говорить лишь применительно к противопоставлению нефинитных и финитных форм соответственно: если в языке есть финитная форма, специально предназначенная для выражения значения одновременности/ неодновременности (предшествования/следования) по отношению к некоторой ситуации, необязательно ситуация общения, то такая форма глагола - есть форма независимого таксиса» (Касевич 1988. 208-209).

В.С. Храковский определяют таксис как категорию, реализуемую в би- и полипредикативных конструкциях, где грамматическими средствами маркируется временная локализация (одновременность, неодновременность, предшествование, следование) двух ситуаций относительно друг друга. (Храковский 2003. 37). Он выделяет следующие типы таксисных отношений: 
одновременность и неодновременность (предшествование, следование). Дальнейшая субкатегоризация позволяет выделить три разновидности хронологического отношения неодновременности (предшествования, следования) (прерываемого, контактного, дистантного) и три разновидности одновременности (полной и неполной двух видов). (Храковский 2003. 37-44).

B.C. Храковский оперирует термином языковеда В.П. Недялкова «таксисные пары» (зависимые/независимые (опорные) и указывает на то, что образующие таксисную пару ситуации прототипически представлены глагольными формами (финитными/ нефинитными). Таксисные формы могут иметь различный категориальный статус, выражаясь: (1) с помощью специализированных нефинитных и финитных глагольных форм; (2) с помощью союзов в совокупности с неспециализированными финитными глагольными формами; (3) с помощью предлогов/послелогов в совокупности с неспециализированными глагольными формами, отглагольными именами, а также с неотглагольными предикатными именами (Храковский 2003. 37-38).

А.В. Бондарко определяет таксис как «выраженное в высказывании значение отношения во времени между действиями (в широком смысле, включая любые репрезентации предикатов в составе предикативного комплекса, элементы которого относятся к одному и тому же временному плану (прошлого, настоящего или будущего)» (Бондарко 1984, 1999, 2011). Категория таксиса включает: «а) одновременность, предшествование и следование (собственно хронологические связи); б) сопряженность во времени основного и сопутствующего действий; в) связь действий во времени в сочетании с причинными, условными, уступительными, пояснительными (Бондарко 1999. 13-14).

\section{Основная часть}

Таксис понимается как выражаемая в полипредикативных конструкциях временная соотнесенность действий в рамках единого темпорального плана, 
при этом полипредикативность высказывания является важным признаком данной функционально-семантической категории. А.В. Бондарко в своих работах подчеркивает релевантность термина «полипредикативный комплекс». По его мнению, данный комплекс включает «разные типы полипредикации в сложных предложениях, предложениях с однородными сказуемыми и сверхфразовых единствах, а также конструкциях с неполнопредикативными (вторично-предикативными) структурами (деепричастными и причастными оборотами)» (Бондарко 2011. 241).

Термин «полипредикация» носит условный характер и распространяется также на различные типы осложненных высказываний, характеризующихся дополнительной предикативностью (Полянский 1991. 12). Таковыми являются, например, предложения с причастными и именными (адъективными, девербативными) конструкциями.

C признаком полипредикативности тесно связан признак аспектуальности, в связи с чем таксисные ситуации трактуются как «аспектуально-таксисные», а также признак полиглагольности (Бондарко 2011. 235; Полянский 1991. 15). Признак полиглагольности предполагает наличие не менее двух глагольных форм (финитных/нефинитных), каждая из которых образует собственную пропозицию (полную или редуцированную) (Полянский 1991. 15-16).

Таксисные значения одновременности/разновременности репрезентируются как в полипредикативных высказываниях, так и в высказываниях с полупредикативными структурами (причастиями, деепричастиями, девербативами, герундиальными конструкциями).

В рамках функционально-семантической концепции таксис трактуется как бицентрическое функционально-семантическое поле, формируемое разными элементами морфологического, лексико-грамматического и синтаксического языковых уровней, и включающее два микрополя: зависимого и независимого таксиса (Бондарко 1984. 79). 
Зависимыц̆ таксис включает временные отношения между главным (основным) и второстепенным (сопутствующим, побочным) действиями, эксплицитная градация которых является базовой характеристикой категориальной семантики зависимого таксиса.

Микрополе зависимого таксиса, конституируемое русскими высказываниями с предложными девербативами, отличается гетерогенностью и различной степенью специализированности и регулярности употребления предложных девербативов. Высказывания с девербативами с таксисообразующими предлогами темпоральной семантики образуют сферу примарного (первичного, хронологического, логически необусловленного, необстоятельственного) таксиса, в то время как высказывания с гетерогенно-таксисными предлогами нетемпоральной семантики эксплицируют значения секундарного (вторичного, обстоятельственного, сирконстантного, фонового, логически обусловленного) таксиса (Архипова 2011, 2012, 2019, 2019a, 2020).

В высказываниях с нетемпоральными предлогами актуализируются секундарно-таксисные значения одновременности, осложненные элементами логической обусловленности (образа действия, каузальности, концессивности, кондициональности, консекутивности, финальности). В высказываниях с итеративными девербативами и глаголами, а также при наличии итеративных квантификаторов возможна актуализация сопряженных итеративно-таксисных категориальных ситуаций одновременности и разновременности (как в «чистом виде, так и осложненных модальными, каузальными, кондициональными, концессивными, консекутивными и другими обстоятельственными значениями логической обусловленности).

В русских высказываниях хронологического (примарного, логически необусловленного, необстоятельственного) типа с девербативами с темпоральными предлогами во время, в течение, после, перед, до, с, при, 
накануне актуализируются примарно-таксисные значения:

одновременности; (2) предшествования (строгого/дистантного/сильного и нестрогого/контактного/слабого); (3) следования (строгого/дистантного/ сильного и нестрогого/контактного/слабого). Например:

В мае, во время рассмотрения импичмента в Госдуме, было принято политическое решение о захоронении мумии [НКРЯ].

C приездом naпbl в нашей жизни кое-что изменилось [НКРЯ].

Накануне приезда Марека Катя допоздна убирала квартиру [НКРЯ].

Ярославль же после отъезда волковцев остался без театра [НКРЯ].

Примарно-таксисную семантику строгого (дистантного, сильного) эксплицируют темпорально-аспектуальные квантификаторы типа: через несколько минут, через полминуты, через неделю, через месяи, на следуюший день, за час, за несколько минут, за два часа, за день, за два дня, за неделю, за месяи, сразу, незадолго и др., указывающие на определенный темпоральный промежуток, имеющий место между «индивидуальными внутренними временами» совершения (протекания) основного действия глагола и сопутствующего действия девербатива. Например:

$3 a$ день перед отъездом вышло предписание, кому ехать при лице государя. [НКРЯ].

Это произошло всего за час до отъезда в аэропорт [НКРЯ].

Теперь информация о каждой партии прибывшего на терминал груза предоставляется в электронном виде таможне уже через несколько минут после прибытия [НКРЯ].

Сразу после отъезда Савинкова из Ставки туда прибыл В.Н. Львов. [НКРЯ].

Секундарно-таксисные значения одновременности актуализируются в полипропозитивных моно- и полисубъектных высказываниях логически обусловленного (секундарного, вторичного, обстоятельственного, 
сирконстантного, фонового, нехронологического) типа с предлогами модальной, кондициональной, каузальной, финальной, концессивной и консекутивной семантики: несмотря на, вопреки, в силу, благодаря, из-за, от, вследствие, ради, для. Действие (процесс, событие), обозначаемое предложным девербативом, носит сопутствующий (секундарный, вторичный, побочный) характер, являясь при этом условием, причиной, уступкой, манерой протекания/совершения или целью основного действия глагольного предиката высказывания. Например:

Торжество праздника годовщины оттенилось и стало более значимым, благодаря приезду президента Латвии Яна Чаксте [НКРЯ].

Из-за охлаждения внутри обитаемого отсека образуется конденсированная вода [НКРЯ]. На основе этого ядра корпорация выпустила три серии процессоров для применения их в сетевых устройствах типа коммутаторов маршрутизаторов, устройствах ввода/вывода и КПК [НКРЯ].

Среди обследованных высказываний особое место занимают высказывания кратного типа, содержащие итеративные девербативы, глаголы и различные итеративные атрибуты и адвербиалы (типа: каждый раз, всякий раз, всегда, редко, иногда, часто, не часто, постоянно, регулярно, каждый день, каждые сутки, каждый месяи, каждый год и др.).

Е.Э. Пчелинцева выделяет русские отглагольные имена следующих семантических типов кратности: (1) мультипликативные (вскрики, вскрикивания, взвизгивания, истощение, колебание); (2) дистрибутивные (с дистрибутивно-суммарной, дистрибутивно-кумулятивной семантикой и с семантикой тотального образа действия (обдаривание, обшаривание, обход, опрашивание, объезд, обыск, рассылание, разбрызгивание, навивание/навивка (гнезд), наброска (песка), накидывание, наметывание (икры), накачка/накачивание (ведра воды), намолачивание, изукрашивание, израсходование, изрисовывание, вытаптывание, вымазывание); итеративные (взмах/взмахивание, глоток/глотание). (Пчелинцева 2012. 63-70). 
Девербативы с семантикой генетической и словообразовательной мультипликативности и итеративности (крики, стоны, вопли, упреки, поиски, встречи, ожидания, обещуания, расставания, вздрагивания, взвизгивания, взмахивание, жужжание, гудение, бормотание, щеебетание, дрожание, подмигивание, кивание), а также дистрибутивности (израсходывание, разбрызгивание, обдаривание, обшаривание, опрашивание, вытаптывание, обход, объезд, обыск) актуализируют мультипликативно-таксисные, дистрибутивно-таксисные и итеративно-таксисные значения одновременности, предшествования и следования.

Инвариантную таксисную семантику одновременности, предшествования или следования в высказываниях кратного типа эксплицирует таксисообразующий предлог (поли- или монотаксисный). Монотаксисные предлоги во время, в течение, с, при, несмотря на, вопреки, в силу, благодаря, из-за, от, вследствие, ради, для и политаксисный предлог при маркируют таксисное значение одновременности, а монотаксисные предлоги до, перед, накануне, после эксплицируют инвариантное таксисное значение разновременности (предшествования или следования). Например:

В иностранных армиях штурмовики используются также для разбрызгивания отравляющих веществ с помощью особых приборов распылителей [НКРЯ].

Все заглядывали в приемную и, несмотря на запрещение, часто пробегали мимо [НКРЯ].

Макс, вопреки ожиданиям, играть не умел, а Зина играла грубо, слишком напряжённо [НКРЯ].

Через некоторое время после поисков Роман узнал, что мать его умерла три с половиной года назад [НКРЯ].

После встреч с отциом трехлетняя девочка возвращалась домой в состоянии глубочайшего шока, со следами побоев на теле [НКРЯ]. 
При наличии итеративных девербативов и/или глаголов, а также итеративных квантификаторов актуализируются: (1) итеративно-примарнотаксисные значения одновременности, предшествования, следования (в высказываниях с темпорально-таксисными предлогами во время, в течение, после, перед, до, с, при, накануне); (2) итеративно-секундарно-таксисные значения, осложненные модальными, каузальными, кондициональными, концессивными, консекутивными и финальными значениями (см. высказывания русского языка с таксисообразующими моносемичными предлогами несмотря на, вопреки, в силу, благодаря, из-за, от, вследствие, ради, для).

В высказываниях с темпорально-таксисными предлогами во время, в течение, после, перед, до, с, при, накануне репрезентируются: (1) итеративнопримарно-таксисные значения одновременности; (2) итеративно-примарнотаксисные значения предшествования; (3) итеративно-примарно-таксисные значения следования; (4) мультипликативно-примарно-таксисные значения одновременности; (5) мультипликативно-примарно-таксисные значения следования; (6) мультипликативно-примарно-таксисные значения предшествования; (7) дистрибутивно-примарно-таксисные значения одновременности; (8) дистрибутивно-примарно-таксисные значения следования; (9) дистрибутивно-примарно-таксисные значения предшествования. Например:

Именно толпилась, так было всегда после прибытия поезда. [НКРЯ].

Утром все корабли при криках и песнях моряков вышли из гавани в море. [НКРЯ].

А при вздрагивании всякий раз меня будила сетка от кровати, которая издавала зловещий звон, визжание и скрежет [НКРЯ].

При дрожании перепонки отраженный пучок света движется вверх и вниз и записывает свой след на пленке; пучок света чертит кривую линию, толщина которой меньше 0,1 мм при амплитуде в несколько миллиметров [НКРЯ]. 
Повсюду мостки (пешеходные, так как вне дороги в плоских местах мелкие торфяники) превращаются при вытаптывании в липкую серую грязь) [НКРЯ].

Во вторник вечером после обысков в «Сибирско-Уральской нефтегазохимической компании» были задержаны трое [НКРЯ].

В высказываниях логически обусловленного (нехронологического, обстоятельственного) типа с предлогами несмотря на, вопреки, в силу, благодаря, из-за, от, вследствие, ради, для репрезентируются следующие разновидности итеративно-секундарно-таксисных категориальных ситуаций одновременности: (1) итеративно-модально-таксисные; (2) итеративнокаузально-таксисные; (3) итеративно-кондиционально-таксисные; итеративно-концессивно-таксисные; (5) итеративно-консекутивно-таксисные; (6) итеративно-финально-таксисные; (7) мультипликативно-модальнотаксисные; (8) мультипликативно-каузально-таксисные; мультипликативно-кондиционально-таксисные; (10) мультипликативноконцессивно-таксисные; (11) мультипликативно-консекутивно-таксисные; (12) мультипликативно-финально-таксисные; (13) дистрибутивно-модальнотаксисные; (14) дистрибутивно-каузально-таксисные; (15) дистрибутивнокондиционально-таксисные; (16) дистрибутивно-концессивно-таксисные; (17) дистрибутивно-консекутивно-таксисные; (18) дистрибутивно-финальнотаксисные. Ср.:

От него же узнал, что, несмотря на обыски Свистунова ... стол Александра III все еще стоит нераспечатанным [НКРЯ].

Несмотря на обещания президента ЕС Хермана Ван Ромпея, никто не торопится спасать «утопающего» [НКРЯ].

Несмотря на стоны бизнесменов, все-таки уменьшается бремя контроля за экономикой [НКРЯ].

Было 30 лет «Известий». Прошло тихо, несмотря на ожидания известиниев [НКРЯ]. 
Над головами, как дымки выстрелов, взлетали от вскриков белые облачка пара [НКРЯ].

Наружное отверстие евстахиевой трубы открывается только при глотании, разговоре, пении и зевоте [НКРЯ].

Только при криках: пришли русские! поднялся страшный переполох: все бросились вон из фанзы, оставив в ней карты, деньги, котомки, чашки и прочий скарб [НКРЯ].

При падении потребления объемы собственной добычи тоже падают вследствие истощения месторождений [НКРЯ].

Итак, сразу хочу напомнить, что первоначально, было сказано следующее: «Но это не очень распространенная поломка, как правило, двигатель горит не из-за перегрева, а вследствие износа топливных магистралей [НКРЯ].

В Москву Солженицын приезжал по неотложным делам, для встреч и для сбора материалов [НКРЯ].

Для поисков оригинальных решений по модернизации микробиологических лабораторий в Литве создан Европейский научный центр [НКРЯ].

\section{Заключение}

Итак, обследованные высказывания русского языка конституируют микрополе зависимого таксиса, отличающееся гетерогенностью, различной степенью прототипичности и регулярности употребления предложных девербативов. Высказывания хронологического типа с таксисообразующими предлогами темпоральной семантики образуют сферу примарного (первичного, хронологического, логически необусловленного) таксиса, в то время как высказывания логически обусловленного типа с гетерогеннотаксисными предлогами нетемпоральной семантики репрезентируют значения секундарного (обстоятельственного, сирконстантного, логически обусловленного таксиса) таксиса. В высказываниях кратного типа с 
итеративными девербативами/глаголами и/или при наличии итеративных квантификаторов актуализируются различные сопряженные итеративнотаксисные категориальные ситуацийи одновременности, предшествования и следования (как в «чистом виде», так и осложненные обстоятельственными элементами логической обусловленности).

\section{Литература}

1- Архипова И.В. (2011). Таксисные отношения в высказываниях с предложными девербативами// Функциональные свойства единиц языка: коллективная монография. Сер. Прикамское научное собрание / Некоммерческое партнерство «Прикамский социальный ин-т»; редкол.: Ерофеева т. и. и др. Пермь. С. 16-46.

2- Архипова И.В. (2012). Кратный таксис в современном немецком языке // Вестник Новосибирского государственного педагогического университета. Т. 9. № 5. C. 95-104.

3- Архипова И.В. (2019). Синкретизм в сфере актуализаџии таксисных значений одновременности // Современная наука: актуальные проблемы теории и практики. Серия: Гуманитарные науки. Москва: Издательство: «Научные технологии». № 12 (2). С. 149-154.

4- Архипова И.В. (2019а). Предложсные девербативы как средство выражения зависимого таксиса // Евразийский гуманитарный журнал. № 4. С. 21-26.

5- Архипова И.В. (2020). Модель функционально-семантического поля таксиса// Современная наука: актуальные проблемы теории и практики. Серия: Гуманитарные науки. Москва: Изд-во: «Научные технологии». № 1. С. 131137.

6- Бондарко А.В. (1984). Функциональная грамматика. -Л.: «Наука. 134 с.

7- Бондарко А.В. (1999). Основы функциональной грамматики: Языковая интерпретация времени / С.-Петерб. гос. ун-т. -СПб.: Изд-во «С. Петерб. унта». $257 \mathrm{C}$.

8- Бондарко А.В. (2011). Общая характеристика семантики и структуры поля таксиса // Теория функциональной грамматики: Введение, аспектуальность, временная локализованность, таксис. Изд. 6-е. -М.: Книжный дом «Либроком», С. 234-242.

9- Касевич В.Б. (1988). Семантика. Синтаксис. Морфология. -М.: «Наука». 309 с.

10- Маслов Ю.С. (1984). Очерки по аспектологии. -Л.: Изд-во «ЛГУ». 263 с. 
11- НКРЯ - Национальный корпус русского языка [Электронный ресурс]. - Режим доступа: URL: http://www.ruscorpora.ru/ (дата обращения: 14.06.2020).

12- Полянский С.М. (1991). О категории таксиса и путях ее исследования (На материале немецкого языка) // Функционально-семантические отношения в лексике и грамматике: Межвуз. сб. науч. тр. / Новосибирск. гос. пед. ин-т; редкол.: С.М. Полянский (отв. ред.) и др. Новосибирск: Изд-во «НГПИ». С. 3 18.

13- Пчелинцева Е.Э. (2012). Семантический признак кратности в русских отглагольных именах действия // Известия Российского Государственного педагогического университета им. А.И. Герцена. № 146. С. 63-70.

14- Храковский В.С. (2003). Категория таксиса (общая характеристика)// Вопросы языкознания. № 2. С. 32-54.

15- Якобсон Р.О. (1972). Шифтеры, глагольные категории и русский язык // Принципы типологического анализа языков различного строя: Сб. статей/ Инт востоковедения. Сост. и предисл. О.Г. Ревзиной. -М.: «Наука». С. 95-114.

\section{Bibliography}

1- Arhipova I.V. (2011). Taksisnye otnoshenija v vyskazyvanijah s predlozhnymi deverbativami// Funkcional'nye svojstva edinic jazyka: kollektivnaja monografija. Cer. Prikamskoe nauchnoe sobranie / Nekommercheskoe partnerstvo «Prikamskij social'nyj in-t»; redkol.: Erofeeva t. i. i dr. Perm'. C. 16-46.

2- Arhipova I.V. (2012). Kratnyj taksis v sovremennom nemeckom jazyke // Vestnik Novosibirskogo gosudarstvennogo pedagogicheskogo universiteta. T. 9. № 5. S. 95-104.

3- Arhipova I.V. (2019). Sinkretizm v sfere aktualizacii taksisnyh znachenij odnovremennosti // Sovremennaja nauka: aktual'nye problemy teorii i praktiki. Serija: Gumanitarnye nauki. Moskva: Izdatel'stvo: «Nauchnye tehnologii». № 12 (2). S. 149-154.

4- Arhipova I.V. (2019a). Predlozhnye deverbativy kak sredstvo vyrazhenija zavisimogo taksisa // Evrazijskij gumanitarnyj zhurnal. № 4. S. 21-26.

5- Arhipova I.V. (2020). Model' funkcional'no-semanticheskogo polja taksisall Sovremennaja nauka: aktual'nye problemy teorii i praktiki. Serija: Gumanitarnye nauki. Moskva: Izd-vo: «Nauchnye tehnologii». № 1. S. 131-137.

6- Bondarko A.V. (1984). Funkcional'naja grammatika. -L.: «Nauka. $134 \mathrm{~s}$.

7- Bondarko A.V. (1999). Osnovy funkcional'noj grammatiki: Jazykovaja interpretacija vremeni / S.-Peterb. gos. un-t. -SPb.: Izd-vo «S. Peterb. un-ta». 257 S. 
8- Bondarko A.V. (2011). Obshhaja harakteristika semantiki i struktury polja taksisa // Teorija funkcional'noj grammatiki: Vvedenie, aspektual'nost', vremennaja lokalizovannost', taksis. Izd. 6-e. -M.: Knizhnyj dom «Librokom», S. 234-242.

9- Kasevich V.B. (1988). Semantika. Sintaksis. Morfologija. -M.: «Nauka». 309 s.

10- Maslov Ju.S. (1984). Ocherki po aspektologii. -L.: Izd-vo «LGU». 263 s.

11- NKRJa - Nacional'nyj korpus russkogo jazyka [Jelektronnyj resurs]. - Rezhim dostupa: URL: http://www.ruscorpora.ru/ (data obrashhenija: 14.06.2020).

12- Poljanskij S.M. (1991). O kategorii taksisa i putjah ee issledovanija (Na materiale nemeckogo jazyka) // Funkcional'no-semanticheskie otnoshenija v leksike i grammatike: Mezhvuz. sb. nauch. tr. / Novosibirsk. gos. ped. in-t; redkol.: C.M. Poljanskij (otv. red.) i dr. Novosibirsk: Izd-vo «NGPI». C. 3-18.

13- Pchelinceva E.Je. (2012). Semanticheskij priznak kratnosti v russkih otglagol'nyh imenah dejstvija // Izvestija Rossijskogo Gosudarstvennogo pedagogicheskogo universiteta im. A.I. Gercena. № 146. S. 63-70.

14- Hrakovskij V.S. (2003). Kategorija taksisa (obshhaja harakteristika) // Voprosy jazykoznanija. № 2. S. 32-54.

15- Jakobson R.O. (1972). Shiftery, glagol'nye kategorii i russkij jazyk // Principy tipologicheskogo analiza jazykov razlichnogo stroja: Sb. statej/ In-t vostokovedenija. Sost. i predisl. O.G. Revzinoj. -M.: «Nauka». S. 95-114.

\section{HOW TO CITE THIS ARTICLE}

Архипова, И. (2021). Categorical Semantics of Dependent Taxis

in Russian Language. Issledovatel'skiy Zhurnal Russkogo Yazyka I Literatury, 9(1). 11-26.

DOI: $10.52547 /$ iarll.17.11

URL: https://www.journaliarll.ir/index.php/iarll/article/view/122

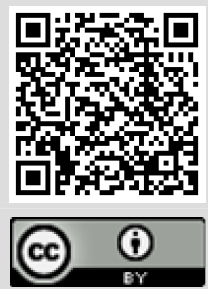


معناشناسى مقولهاى بازكنشهاى وابسته در زبان روسى

$$
\begin{aligned}
& \text { ايرينا ويكتورونا آرخييووا' }
\end{aligned}
$$

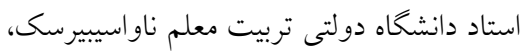

$$
\begin{aligned}
& \text { ناو اسيبيرسك، روسيه. }
\end{aligned}
$$

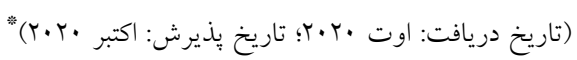

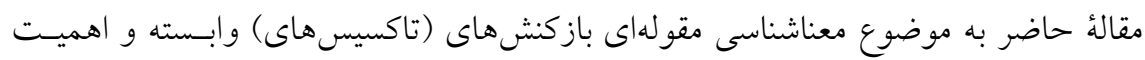

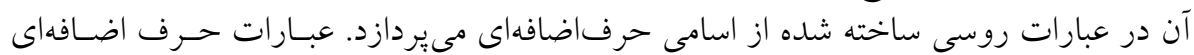

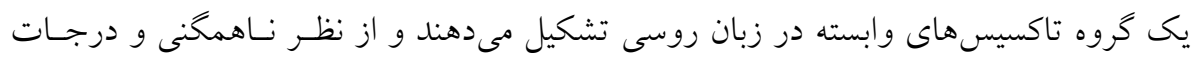

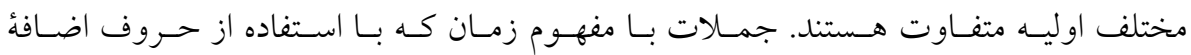

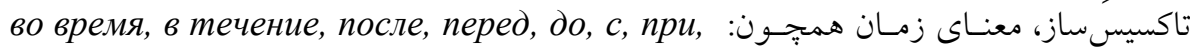
накануне

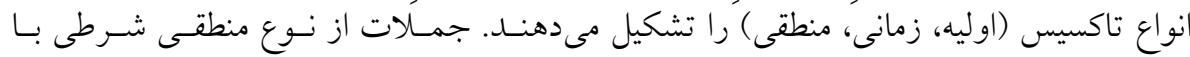

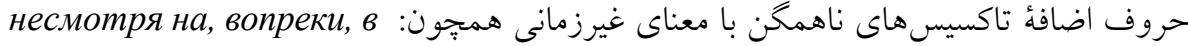
с силу, благодаря, из-за, от, вследствие, ради, для

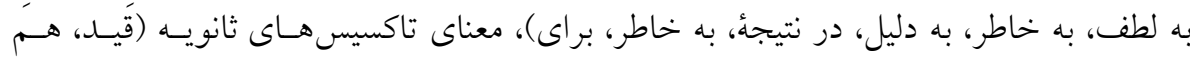

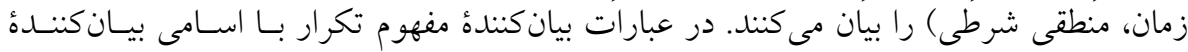

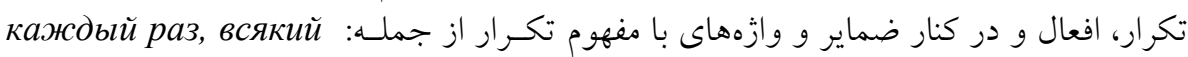
раз, часто, всегда, иногда, регулярно

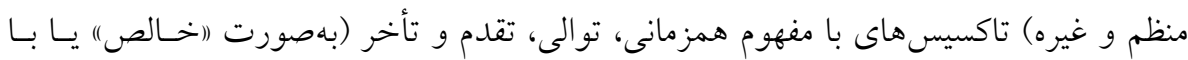
اجزاى با مفهوم قيدى شرطى منطقى) بيان مىشوند.

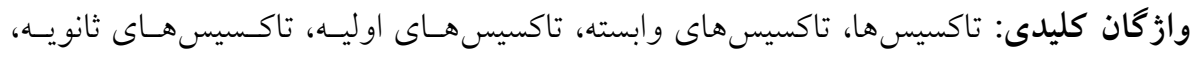

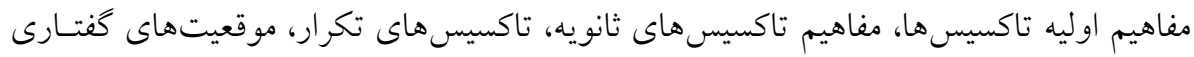
مقولهاى.

1. E-mail: irarch@yandex.ru

$$
\text { * توع مقاله: علمى - يزوهشى }
$$

